\title{
AC 2010-695: CHANGING THE MINDSET: THE LECTURER'S RESPONSIBILITY WHEN PRESENTING A FIRST YEAR COURSE.
}

\section{George Gibbon, University of The Witwatersrand}

George Gibbon obtained a National Diploma in 1973 and was awarded an MSc(Eng) in 1990 and a PhD in 1995 by the University of the Witwatersrand. Before joining Wits in 1986 he worked at S A Philips (now Philips South Africa) from 1971 to 1974, and the Chamber of Mines Research Laboratories (1974-1986) where he was responsible for the design and development of instrumentation for seismic, rock mechanic and sequential blasting research. His research interests include measurement systems, marine electromagnetic radiation and its influence on sharks, and engineering education.

\section{Ian Jandrell, University of the Witwatersrand}

Ian R Jandrell PhD, FSAIEE, MIEEE is a Registered Professional Engineer, Personal Professor and Head of the School of Electrical and Information Engineering at the University of the Witwatersrand, Johannesburg, where he also holds the CBi-electric Chair of Lightning. Ian is joint leader of the High Voltage and the Lightning/EMC Research Groups and is a rated scientist with a National Research Foundation (NRF) C2-rating. He is the author or co-author of more than 100 papers in the areas of High Voltage Engineering, Earthing and Lightning Protection and Industrial EMC. From 1993-1997 Ian was a member of Council of the South African Institute of Electrical Engineers (SAIEE) and Chairperson of the Education and Training Committee from 1994-1997. From 1997-2001 Ian was a member of South Africa Qualifications Authority (SAQA) National Standards Body 06: Manufacturing, Engineering and Technology, representing the Engineering Professions. Since 1996 Ian has led accreditation teams in the assessment of numerous University Engineering Programmes on behalf of the Engineering Council of South Africa (ECSA), and has been a team member for the assessment of many other programmes. 


\title{
Changing the Mindset: The Lecturer's Responsibility when Presenting a First Year Course.
}

\begin{abstract}
Students entering tertiary education are coming from a predominantly procedural learning (rote) background and are unprepared to perform in a predominantly conceptual thinking (relationship between items of knowledge) environment. Since 2004 changes have been implemented in the Electric Circuits course to develop both conceptual and critical thinking. This has resulted in an increased pass rate for the course. However, analysis of the exam papers and second year success revealed that the student's were optimizing their success by leaving out sections of the work that they regarded as "difficult". As all the sections are the essential basic knowledge required for the second year courses the course and the final exam was divided into four topics all of which must be passed to pass the course. Initial results indicate that many students have changed their preparation process to comply with the new rules.
\end{abstract}

\section{Introduction}

Students entering tertiary education are coming from a predominantly procedural learning background and are unprepared to perform in a predominantly conceptual thinking engineering education environment. The definitions of procedural and conceptual learning, in terms of engineering education, are best described by McCormick ${ }^{1}$. Procedural knowledge is defined as "know how to do it" knowledge, best mastered by rote learning, while conceptual knowledge "is the relationship between 'items' of knowledge". This inability to think and learn conceptually is not always apparent in the first year at university, as the courses are presented at the introductory level of basic concepts and "language", and the students can still achieve success by applying their well developed rote learning skills.

Since 2004 changes have been implemented in the Electric Circuits course, one of two engineering courses in first year, to develop conceptual and critical thinking in our first year students. Our students come from diverse secondary school backgrounds; some are well resourced while others are almost hopelessly under resourced in terms of facilities, teaching materials and teaching staff. Many of the students are also studying engineering for reasons that do not include an interest in, or an aptitude for, engineering. Some of the reasons are the availability of scholarships and bursaries to study engineering, parental pressure and future financial security after obtaining an engineering degree.

In 2004 the changes included extending the course over two semesters, adding a critical thinking component and changing the laboratory concepts. In 2005 formal tutorials were dropped and self-learning concept in the laboratories was extended. Developing a "global" learning approach by integrating the laboratory tasks with the lectures was introduced in 2007. In 2009 the requirement for the students to pass all topics in the course to pass the course, and not just an aggregate mark, was introduced. 
The reasons for the changes and the influence that these changes have had on both the attitude of the students and their results are presented in this paper.

\section{Motivation for Change}

There is an unacceptably high failure rate in both the second and third years of study in the four year degree program. As a result there are large numbers of repeat students in both years.

Analysis of the second year results for 2004 to 2009 show that the numbers of repeating students in the class range from $27 \%$ to $50 \%$. Similar trends are shown in third year with the added moral problem of many of the students being excluded and leaving the university, after up to five years of study, with nothing more than their School Leaving Certificate.

In the second and third year the engineering courses require conceptual thinking and learning which was clearly not developed in the previous years of study. In the first year we can blame the poor secondary school system for not providing us with the correct "raw material" for our education process, but by third year we should have provided the required processes to change the "raw material" into what our system requires. This is the responsibility of the first year courses and lecturers. An added responsibility, with our diverse intake, is to "persuade" students with no interest in engineering to pursue other careers at an early stage, and not after up to five years of failed study.

In 2003 it was decided that the two courses presented by the School of Electrical and Information Engineering to our first year students would be changed to try and prepare our students for the subsequent years of study. English literature was added to the Engineering Design course to improve both the English literacy ${ }^{2}$ and critical thinking ${ }^{3}$ abilities of the students. Major changes were also made to the Electric Circuits course and these will be discussed in the next sections.

\section{Changes to the Electric Circuits Course in 2004 to 2008}

The changes in 2004 were aimed at reducing the students' dependence on their "teachers" and to develop critical thinking. The changes were as follows ${ }^{4}$ :

- The course was extended from one semester to two semesters but with less contact time. This was to give the students more time to assimilate the basic concepts.

- A weekly "informal" lecture replaced a formal lecture where any topic, except "Electric Circuits", can be discussed and debated. The topics include current affairs, AIDS, sex, religion, evolution, University policy etc.

- Compulsory formal small group tutorials were discontinued and were run on a voluntary basis with the same tutorial material as was used in the previous years.

- Laboratories were changed from formal group assignments to individual circuit building and testing. This allows for the "weaker" students more time to get to familiarize themselves with the basic laboratory equipment, circuit construction and measurement techniques.

- Two "take home tests" were introduced in the first semester for the students to gauge their own progress. 
To have a reference point to compare the results of the changes introduced, the exam and the two tests for marks were kept essentially the same as in previous years. The results were surprisingly good. The class average for the course was $68 \%, 10 \%$ higher than the average of the previous three years and the pass rate increasing from 77\% (2001), 76\% (2002) and 65\% (2003) to 90\% in 2004.

As the tutorial sessions were under utilized in 2004, they were discontinued and replaced with "tutorials on demand", during the laboratory sessions, in 2005. The number of laboratory tasks were increased and changed to enhance the self-learning process. The examination style was also changed and included a deeper examination of the students' conceptual abilities. As a result the 2005 final marks were not as good as in 2004 with a $58 \%$ pass rate with a similar pass rate of $61 \%$ in 2006. Analysis of the examination results indicated the most of the students had done badly with the conceptual questions in the exam. Analysis of the students' behavior in 2006 indicated that although the lecturers felt that the laboratories were directly related the material being presented during lectures the students saw them as being totally unrelated.

As the authors believe that conceptual knowledge is best developed with "hands-on" experience, major changes were again made to both the laboratories and lecturing styles in 2007. These changes were made to introduce a concept of "global learning" where the laboratory experiments undertaken by individual students are directly related to the material being covered in the lectures 5 . The "global learning" concept is based the best teaching method of induction, as defined by Felder and Silverman ${ }^{6,7}$. The pass rate for the course improved to $80 \%$ in 2007 and $74 \%$ in 2009, showing an improvement for two successive cohorts.

Students entering the university in 2009 were the product of both a major curriculum change and a new Senior Certificate examination in the secondary school system. The changes resulted in increased marks for both Mathematics and the Physical Sciences and an influx of students being accepted for engineering. The numbers in the Electric Circuits course increased from 127 in 2008 to 249 in 2009. Initial analysis by the Faculty of Engineering indicates that about $60 \%$ of the students, across all the engineering schools in the Faculty, should not have been accepted. As a result of 2009 being, hopefully, an "outlier" year it has not been fully included for analysis in this paper.

\section{Analysis of the Second Year Results}

Changes to a course in a degree program should not only be aimed at improving the pass rate or the students' experience, but also to supply fully prepared students to the subsequent years of study. This is especially true for a first year course. The overall pass rate for the second year of study indicates 15\% improvement from 2004 to 2008. Unfortunately the overall pass rate does not tell the whole story. Analysis at individual student level indicates that it is the repeat students that are doing better the second time around, and not the students doing second year subjects for the first time.

Table 1 shows the second year results from 2004 to 2009 for students entering second year for the first time. Included is also the percentage of repeats in the class. The results shown in table 1 do not include the results of supplementary exams granted to students who qualify. The analysis 
was done on first time, first chance results as any other route to success requires extra resources both from the students and the university. Repeating students are best thought of as "eddy currents" using reactive power and wasting energy, which could be utilized more efficiently elsewhere.

Table 1: Second year results from 2004 to 2009

\begin{tabular}{|c|c|c|c|c|}
\hline & $\begin{array}{c}\text { Total } \\
\text { students }\end{array}$ & $\begin{array}{c}\text { New } \\
\text { students }\end{array}$ & $\begin{array}{c}\text { Passed all } \\
\text { subjects }\end{array}$ & $\begin{array}{c}\text { \% Repeats } \\
\text { in the class }\end{array}$ \\
\hline 2004 & 172 & 126 & $30 \%$ & $27 \%$ \\
\hline 2005 & 170 & 100 & $38 \%$ & $41 \%$ \\
\hline 2006 & 119 & 58 & $26 \%$ & $51 \%$ \\
\hline 2007 & 141 & 69 & $39 \%$ & $51 \%$ \\
\hline 2008 & 149 & 80 & $35 \%$ & $46 \%$ \\
\hline 2009 & 132 & 70 & $31 \%$ & $47 \%$ \\
\hline
\end{tabular}

Analysis of the 2007 and 2008 exam papers revealed that the student's were optimizing their success by leaving out sections of the work (operational amplifiers and AC theory) that they regarded as "difficult". This is the essential basic knowledge required for the second year courses. For analysis purposes the examination results for the Circuits course was divided into four topics as follows:

\section{Topic 1: Concepts}

- Basic electrical concepts.

- Inductors and capacitors.

- Energy and power.

\section{Topic 2: Analysis Techniques}

- Network theorems and laws.

- Systematic circuit analysis.

- Two terminal networks.

\section{Topic 3: Laboratory Concepts and Techniques}

\section{Topic 4: Complex Real Circuits}

- Operational amplifiers.

Table 2 shows the achievements of students who passed Electric Circuits in 2007 and 2008 in their second year of study terms of passing all the topics in Electric Circuits.

Table 2: Passing all topics and success in second year.

\begin{tabular}{|c|c|c|c|c|c|}
\hline & $\begin{array}{c}\text { Total number } \\
\text { of students }\end{array}$ & $\begin{array}{c}\text { Failed a } \\
\text { component }\end{array}$ & $\begin{array}{c}\text { Failed a } \\
\text { subject }\end{array}$ & $\begin{array}{c}\text { Passed all } \\
\text { components }\end{array}$ & $\begin{array}{c}\text { Failed a } \\
\text { subject }\end{array}$ \\
\hline $\mathbf{2 0 0 8}$ & 103 & $38 \%$ & $79 \%$ & $62 \%$ & $55 \%$ \\
\hline $\mathbf{2 0 0 9}$ & 73 & $58 \%$ & $79 \%$ & $42 \%$ & $42 \%$ \\
\hline
\end{tabular}

The results show that students who pass all topics in Electric Circuits are less likely to fail a subject in second year at their first attempt. In both years $79 \%$ of the students who failed a topic 
also failed one or more subject in second year as apposed to 55\% (2008) and 42\% (2009) of the students who passed all topics. Students with marks as high as $80 \%$ for Electric Circuits, and failing only one topic, also failed second year subjects such as Electronics and Electrical and Magnetic Systems.

\section{Changes to the Electric Circuits Course in 2009}

In 2009 it became a requirement for the students to pass all topics in the Electric Circuits course as well as getting the minimum $50 \%$ for the course. Students who got a "pass" mark and fail one or more topics are given a result of "failed component" (FCOMP) and the course is recorded as failed.

The marking criterion was also changed and more marks were allocated to the conceptual thinking questions and conceptual sections within questions. The students were informed of all the requirements to pass the course and the mark allocation in the Course Brief and Outline ${ }^{8}$ for the course and continuously during lectures throughout the year. The tests were also marked using the same criteria and returned to the students.

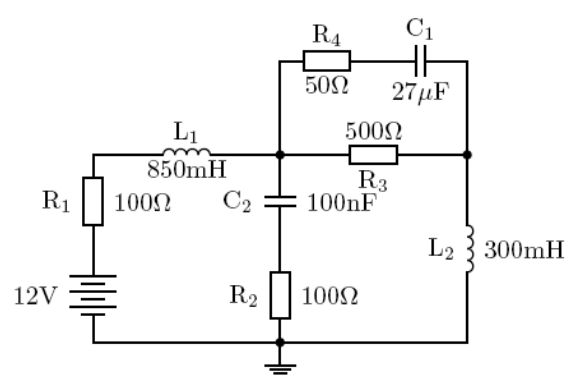

Figure 1: A conceptual thinking exam question

Figure 1 shows an example where the students' lack of conceptual thinking was apparent. The students were required determine the current through, and the voltage across each component in the circuit. The average mark for the question was $38 \%$ as most missed the DC source and developed complex equations which were never solved.

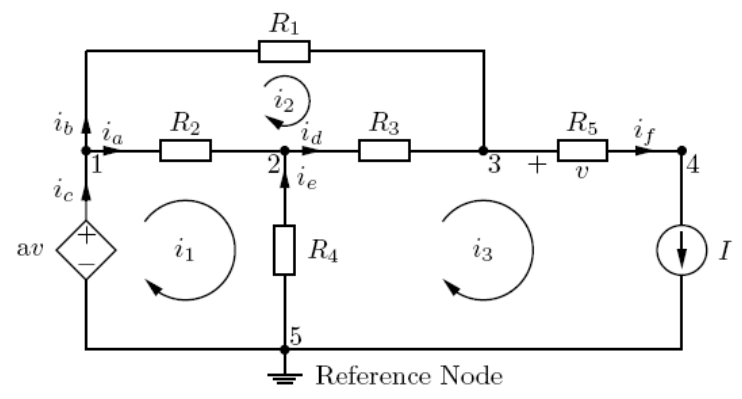

Figure 2: Mesh analysis

The class average for the class for the circuit shown in figure 2 was $34 \%$. The students were very good at manipulating the simultaneous equations into matrix form (procedural knowledge) but 
had great difficulty using Kirchhoff's current laws to get the initial currents to obtain the simultaneous equations. Marks were weighted heavily towards obtaining the initial equations.

Of the 101 students who had a "passing mark" for Electric Circuits in 2009, thirty six failed a component and as a result the course. Of these twenty seven were granted a supplementary examination of which twenty six passed the failed topic. Hopefully this has forced these students to master some of the conceptual thinking required for engineering courses.

The requirement to pass all topics has forced a change in the mindset of the students. Of the students who passed in 2009 only $36 \%$ failed a component compared to $57 \%$ in 2008 and $47 \%$ in 2007.

Analysis of other courses in the degree program show that similar problems exist. The 2009 results show that in the second year Electric and Magnetic Systems course only $10 \%$ of the students, who passed, passed all six topics.

Students have always struggled with Signals and Systems and Control presented in the second semester in the third year of study. Both these courses rely on Mathematical Methods presented in the first semester which has two topics, namely Complex Variables and Integral Theorems and Applied Complex Variables. The students have optimized their marks by concentrating on Applied Complex Variables where the average for the exam was $69 \%$ with a $75 \%$ pass rate. In contrast the average for the exam for the Complex Variables and Integral Theorems topic was $34 \%$ with a pass rate of $22 \%$. From 2010 the students will be required to pass both topics to pass the course.

\section{Conclusion}

On the surface it seems harsh to fail students who essentially have a pass mark for the course, but there is a moral responsibility not to allow under-prepared students to proceed to the next year of study where they will have very little chance of succeeding. The results show that for a course to be affective it must prepare the students for the requirements of future courses in the degree program. Students should not be given false expectations by being allowed to proceed while unprepared to succeed in the next course.

Unfortunately lecturers presenting first year courses have the added problem of changing the mindset of students coming from a predominantly procedural learning secondary school system and have to change a culture of learning. They must also make sure the students have adequate skills and knowledge to be successful in the subsequent courses and even have to take the responsibility for filtering out unsuitable students.

This cannot be achieved by just changing presentation styles and course requirements in just one or two courses but in all first year courses. Changes such as the requirement to pass all topics and mark allocation biased towards conceptual thinking must also be implemented in all the courses in the degree program. Students have the right to come to university and be trained in such a way that the majority can pass all the courses the first time at the standards and levels required for registration as a Professional Engineer. 


\section{Bibliography}

1. R. McCormick, "Conceptual and Procedural Knowledge," International Journal of Technology and Design Education, vol. 7, pp. 141-159, 1997.

2. G. J. Gibbon, K. Nixon, and M. Nixon, "Analysing the raw material: Who are our first years?" in Engineering Education for Sustainable Development. Pretoria: 3rd African Regional Conference on Engineering Education, Sept 2006, pp. 399-407.

3. S. D. Brookfield, Developing Critical Thinkers. Challenging adults to explore alternative ways of thinking and acting. San Francisco: Jossey-Bass, 1987.

4. G. J. Gibbon, I. R. Jandrell, and D. Rubin, Innovations 2006: World Innovations in Engineering Education and Research. Arlington: iNEER, 2006, ch. 4: Shifting the Responsibility of Learning in First-Year Electrical Engineering Students, pp. 27-38.

5. G. J. Gibbon, Innovations 2009: World Innovations in Engineering Education and Research. Arlington: iNEER, 2009, ch. 3: Using Inductive and Global Learning Presentation Styles in an Electric Circuits Course, pp. 23-30.

6. R. M. Felder and L. K. Silverman, "Learning and teaching styles in engineering education," Engineering Education, vol. 78, no. 7.

7. R M Felder. "Learning and Teaching Styles in Engineering Education: Author's Preface". [Online]. Available: http://www4.ncsu.edu/unity/lockers/users/f/felder/public/Papers/LS-1988.pdf.

8. School of Electrical and Information Engineering, University of the Witwatersrand, Johannesburg. "Elen1000 electric circuits, course brief and outline 2009". [Online]. Available: http://www.ee.wits.ac.za/undergraduate/2009cbos/1000-2009.pdf. 